\title{
Hyperpolarization-Activated Cyclic Nucleotide-Gated Channels and cAMP-Dependent Modulation of Exocytosis in Cultured Rat Lactotrophs
}

\author{
Ana I. Calejo, ${ }^{1,2 *}$ Jernej Jorgačevski, ${ }^{2,4 *}$-Boštjan Rituper, ${ }^{2}{ }^{\oplus}$ Alenka Guček, ${ }^{2}{ }^{\odot P a t r i ́ c i a ~ M . ~ P e r e i r a, ~}{ }^{1}$ \\ Manuel A.S. Santos, ${ }^{1}$ Maja Potokar, ${ }^{2,4}$ Nina Vardjan, ${ }^{2,4}$ Marko Kreft, ${ }^{2,3,4}$ Paula P. Gonçalves, ${ }^{1}$ and Robert Zorec ${ }^{2,4}$ \\ ${ }^{1}$ Centre for Environmental and Marine Studies \& Departamento de Biologia, Universidade de Aveiro, 3810-193 Aveiro, Portugal, ${ }^{2}$ Laboratory of \\ Neuroendocrinology-Molecular Cell Physiology, Institute of Pathophysiology, Faculty of Medicine, and ${ }^{3}$ Biotechnical Faculty, University of Ljubljana, 1000 \\ Ljubljana, Slovenia, and ${ }^{4}$ Celica Biomedical Center, 1000 Ljubljana, Slovenia
}

Hormone and neurotransmitter release from vesicles is mediated by regulated exocytosis, where an aqueous channel-like structure, termed a fusion pore, is formed. It was recently shown that second messenger cAMP modulates the fusion pore, but the detailed mechanisms remain elusive. In this study, we asked whether the hyperpolarization-activated cyclic nucleotide-gated (HCN) channels, which are activated by cAMP, are involved in the regulation of unitary exocytic events. By using the Western blot technique, a real-time PCR, immunocytochemistry in combination with confocal microscopy, and voltage-clamp measurements of hyperpolarizing currents, we show that HCN channels are present in the plasma membrane and in the membrane of secretory vesicles of isolated rat lactotrophs. Single vesicle membrane capacitance measurements of lactotrophs, where HCN channels were either augmented by transfection or blocked with an HCN channel blocker (ZD7288), show modulated fusion pore properties. We suggest that the changes in local cation concentration, mediated through HCN channels, which are located on or near secretory vesicles, have an important role in modulating exocytosis.

Key words: cAMP; capacitance measurements; exocytosis; HCN channels; lactotrophs; RT-PCR

\section{Introduction}

Communication between cells is of key importance for multicellular organisms, and secretory vesicles containing signaling molecules play a vital role in this process (Jorgačevski et al., 2012). Secretory vesicles are trafficked to the plasma membrane (Potokar et al., 2011), where they dock, get primed, and finally fuse with the plasma membrane. The transition from nonfused to fully fused vesicle proceeds through a hemifused stage, then a fusion pore is formed, and finally, the expansion of the fusion pore results in full fusion of the vesicle membrane with the plasma membrane (Chernomordik and Kozlov, 2008). However, not all vesicles complete all these transitions at once. Some vesi-

\footnotetext{
Received Dec. 18, 2013; revised Sept. 30, 2014; accepted 0ct. 6, 2014

Author contributions: A.I.C., J.J., B.R., A.G., P.M.P., M.A.S.S., P.P.G., and R.Z. designed research; A.I.C., J.J., B.R., A.G., and P.M.P. performed research; M.K. contributed unpublished reagents/analytic tools; A.I.C., J.J., B.R., P.M.P., and M.P. analyzed data; A.I.C., J.J., B.R., A.G., P.M.P., M.A.S.S., M.P., N.V., P.P.G., and R.Z. wrote the paper.

This work was supported by the Ministry of Higher Education, Sciences, and Technology of the Republic of Slovenia (P3 310; J3 3654; J3 4051; J3 4146); the Portuguese Foundation of Science and Technology of the Portuguese Ministry of Sciences, Technology, and High Education (Bilateral Agreement between Portugal and Slovenia; Project 441.00 Slovenia, SFRH/BD/41217/2007 to A.I.C.). The funders had no role in study design, data collection and analysis, decision to publish, or preparation of the manuscript. We kindly acknowledge Dr. Ana Moroni (Milan, Italy) and Dr. S. Stojilkovic (Bethesda, MD, USA) for their help with HCN2 cloning and discussions.

*A.I.C. and J.J. contributed equally to this work.

The authors declare no competing financial interests.

Correspondence should be addressed to Professor Robert Zorec, Institute of Pathophysiology, Faculty of Medicine, University of Ljubljana, Zaloška 4, 1000 Ljubljana, Slovenia. E-mail: robert.zorec@mf.uni-lj.si.

DOI:10.1523/JNEUROSCI.5290-13.2014

Copyright $\odot 2014$ the authors $\quad 0270-6474 / 14 / 3315638-10 \$ 15.00 / 0$
}

cles are engaged in transient exocytosis for minutes before full fusion (Jorgacevski et al., 2010). Fusion pore conductance $\left(G_{\mathrm{p}}\right)$, a parameter proportional to the fusion pore diameter of the same vesicle, is relatively constant and has been shown to depend on the vesicle diameter (Jorgacevski et al., 2010).

Our previous results indicate that cAMP has a biphasic modulatory role in the release of prolactin (PRL) from lactotrophs, likely through modulating unitary exocytic events, where lower cAMP levels augment exocytosis and higher cAMP values inhibit exocytosis (Calejo et al., 2013). It has been proposed that cAMP can affect exocytosis by acting (1) through a protein kinase A (PKA)-dependent mechanism (Kasai et al., 2002), (2) via the exchange protein directly activated by cAMP (Epac; de Rooij et al., 1998), and (3) directly on the hyperpolarization-activated and cyclic nucleotide-gated (HCN) channels (Seino and Shibasaki, 2005). cAMP facilitates the opening of HCN channels by shifting the activation curve to more positive voltages, which results in a flux of $\mathrm{Na}^{+}, \mathrm{K}^{+}$, and $\mathrm{Ca}^{2+}$ (Gauss et al., 1998; Yu et al., 2004; Michels et al., 2008). These specific cation currents are present in most neuroendocrine cells, including lactotrophs (GonzalezIglesias et al., 2006a; Stojilkovic et al., 2012). HCN channels are arranged in a homotetrameric or heterotetrameric configuration, depending on the combination of the four known isoforms (HCN1-HCN4). All HCN channel isoforms are expressed in the pituitary gland, where the HCN2 mRNA transcript is most abundant (Kretschmannova et al., 2012). 
To address the question of whether $\mathrm{HCN}$ channels regulate exocytosis in neuroendocrine cells, we used rat pituitary lactotrophs, which are, due to the robust secretory activity of relatively large vesicles, an excellent model for studying exocytosis (Vardjan et al., 2007; Jorgacevski et al., 2008, 2010). We report that the $\mathrm{HCN} 2$ isoform is localized in the plasma membrane and likely in a fraction of PRL-containing vesicles in single isolated pituitary lactotrophs. By using the cell-attached patch-clamp technique to monitor unitary exocytic events, we demonstrate that HCN2 channels modulate exocytosis by presumably changing the local concentration of cations.

\section{Materials and Methods}

Ethics statement. Male Wistar rats were killed according to the International Guiding Principles for Biomedical Research Involving Animals developed by the Council for International Organizations of Medical Sciences and Animal Protection Act (Official Gazette of the Republic of Slovenia (RS), no. 40/85, 22/87, 43/07). The procedures using animals were approved by the Veterinary Administration of the RS. The protocol for the killing of the animals used in our study was approved by the Veterinary Administration of the Ministry for Agriculture and the Environment of the RS (permit no. 34401-29/2009/2), issued on April 22, 2009. We have followed the Rule of Three R's to reduce the impact of research on animals.

Cell cultures. Lactotrophs were isolated according to the previously described method (Ben-Tabou et al., 1994; Rituper et al., 2013). After isolation, lactotrophs were plated onto poly-L-lysine-coated glass coverslips and kept in high-glucose DMEM (Invitrogen) with 10\% newborn calf serum and L-glutamine at $37^{\circ} \mathrm{C}$ with $95 \%$ humidity and $5 \% \mathrm{CO}_{2}$.

Western blot. Total lysates of pituitary gland were prepared using RIPA buffer supplemented with protease inhibitor mixture (Roche). Proteins were loaded in $4-15 \%$ SDS-PAGE gel and transferred to a polyvinylidene fluoride membrane (GE Healthcare) for $1 \mathrm{~h}$ at $100 \mathrm{~V}$ and $4^{\circ} \mathrm{C}$. Membranes were incubated with polyclonal rabbit anti-HCN2 antibodies (1: 200; Alamone) in 5\% w/v nonfat dry milk, $1 \times$ Tris-buffered saline (TBS), $0.1 \%$ Tween 20 (TBS-T), overnight at $4^{\circ} \mathrm{C}$ with constant agitation. Afterward, they were washed out and incubated with secondary antibodies (Irdye680 Red anti-rabbit IgG, 1:10,000; Li-Cor Biosciences) in the same buffer and washed again in TBS. The monoclonal rabbit antitubulin antibodies (1:500; Abcam) were applied under the same conditions to label tubulin as the loading control. Using an Odyssey infrared imaging system (Li-Cor Biosciences), membranes were scanned for fluorescence emission at $700 \mathrm{~nm}$ and analyzed with the system's software.

Real-time PCR. Freshly isolated lactotrophs were incubated at $37^{\circ} \mathrm{C}$ for $12 \mathrm{~h}$, frozen in liquid $\mathrm{N}_{2}$, and stored at $-80^{\circ} \mathrm{C}$. Total RNA and genomic DNA (gDNA) were extracted from lactotroph cultures using an AllPrep DNA/RNA/Protein Mini Kit (Qiagen), according to the manufacturer's protocol. A total of $2 \mu \mathrm{g}$ of total RNA was reverse transcribed by the SuperScript II Reverse transcriptase enzyme (Invitrogen) with oligo $(\mathrm{dT})_{12-18}$ primers at $42^{\circ} \mathrm{C}$ for $1 \mathrm{~h}$. A real-time PCR was performed on a 7500 Real-Time PCR System (Applied Biosystems), using Platinum SYBR Green qPCR SuperMix-UDG (Invitrogen), according to the manufacturer's instructions. Primer sets were chosen according to previously published data (El-Kholy et al., 2007): the HCN2 forward primer was GGG AAT CGA CTC CGA GGT CTA C and the reverse primer was AGA CTG AGG ATC TTG GTG AAA CG; for $\beta$-actin, the forward primer was TAG CCA TCC AGG CTG TGT TG and the reverse primer was GGA GCG CGT AAC CCT CAT AG. $\beta$-Actin was used as an endogenous control for normalization. Determination of PCR efficiency and specificity was done by observing the standard and melting curves, respectively, for all primer sets. Reverse transcriptase-minus and nontemplate controls were performed for all samples. All data were performed in triplicate and are representative of three independent experiments. The quantity of HCN2 and $\beta$-actin was calculated based on standard curves produced from gDNA, and relative $\mathrm{HCN} 2$ channel transcript abundance was determined for a specific amount of total RNA using $\beta$-actin as control.

Immunocytochemistry and confocal microscopy. For immunocytochemistry, cells were fixed ( $4 \%$ formaldehyde, $15 \mathrm{~min}$, room tempera- ture (RT)) and permeabilized (0.1\% Triton X-100, 10 min, RT). To reduce nonspecific binding of antibodies, cells were incubated in $3 \%$ bovine serum albumin and $10 \%$ goat serum in PBS $\left(1 \mathrm{~h}, 37^{\circ} \mathrm{C}\right)$. Cells were then labeled first with primary mouse polyclonal anti-HCN2 antibodies (1:50; Abcam) or rabbit polyclonal anti-PRL antibodies (1:40; Millipore Bioscience Research Reagents) and then with secondary antibodies conjugated to Alexa Fluor 488 or Alexa Fluor $546\left(1: 600,45 \mathrm{~min}, 37^{\circ} \mathrm{C}\right.$; Invitrogen). The plasma membrane was labeled before fixation $(2 \%$ formaldehyde, $10 \mathrm{~min}$, RT) with $5 \%$ Vybrant $\mathrm{DiD}\left(\mathrm{DiD} ; 4 \mathrm{~min}, 37^{\circ} \mathrm{C}\right.$; Invitrogen). Immunolabeled cells were recorded with an inverted confocal microscope (Zeiss LSM 510) equipped with an oil-immersion PlanApochromatic objective (63×; numerical aperture, 1.4). For excitation of Alexa Fluor 488, an Ar-ion laser was used in combination with a bandpass emission filter $(505-530 \mathrm{~nm})$. For excitation of Alexa Fluor 543 , a He-Ne laser was used in combination with a long-pass emission filter (cutoff, $<560 \mathrm{~nm}$ ). A He-Ne laser at $633 \mathrm{~nm}$ was used for excitation of DiD in combination with a long-pass emission filter, with the cutoff of $<650 \mathrm{~nm}$. We analyzed the colocalization of respective fluorescent markers by using ColocAna software (Celica Biomedical) that counts red, green, and colocalized pixels. The colocalization was calculated for all pixels above the threshold ( $25 \%$ of maximum green and red fluorescence intensity) and was expressed as the percentage of colocalized marker pixels. The mean fluorescence was determined for the whole cell and for the plasma membrane and cell interior separately, using custom software written for Matlab (MathWorks). Images of cells were separated into the cell interior and the cell periphery (plasma membrane) by manually delimiting the perimeter of the cells according to the DiD signal. The mean fluorescence intensity was then automatically calculated for the rim (plasma membrane $\pm 0.35 \mu \mathrm{m}$, which is the mean diameter of PRL-containing vesicles; Zorec et al., 1991; Angleson et al., 1999) and in the region positioned centrally to the rim (see Fig. 2).

Transfection. Twenty-four hours after isolation, the lactotrophs were cotransfected with plasmid DNA (pDNA) encoding the HCN2 channel isoform (Vaccari et al., 1999) and pDNA encoding-enhanced green florescence protein (EGFP). Lipofectamine (Invitrogen) transfection reagent was applied according to the manufacturer's guidelines. Electrophysiologic recordings of membrane capacitance $\left(C_{\mathrm{m}}\right)$ and hyperpolarizing currents $\left(I_{\mathrm{h}}\right)$ were performed on EGFP-positive cells only.

Electrophysiologic measurements of $\mathrm{C}_{m}$. Cell-attached capacitance measurements were performed with a dual-phase lock-in patch-clamp amplifier (1591 Hz; SWAM IIC, Celica Biomedical). All experiments were performed at RT. We used fire-polished pipettes heavily coated with Sylgard and with resistance of 3-6 M $\Omega$. The bath and pipettes contained extracellular solution, which consisted of $10 \mathrm{~mm} \mathrm{HEPES} / \mathrm{NaOH}, \mathrm{pH} 7.2$, $10 \mathrm{~mm}$ D-glucose, $130 \mathrm{~mm} \mathrm{NaCl}, 8 \mathrm{mM} \mathrm{CaCl}_{2}, 1 \mathrm{mM} \mathrm{MgCl}_{2}$, and $5 \mathrm{~mm} \mathrm{KCl}$ with or without $100 \mu \mathrm{M}$ 4-ethylphenylamino-1,2-dimethyl-6methylaminopyrimidinium chloride (ZD7288, Tocris Bioscience). A sine wave $(111 \mathrm{mV} \mathrm{rms})$ was applied to the pipette and the pipette potential was held at $0 \mathrm{mV}$. After recording for several minutes, the cells were stimulated with $10 \mathrm{~mm}$ N6,2'-O-dibutyryl adenosine- $3^{\prime}, 5^{\prime}$-cyclic monophosphate (dbcAMP). During the experiments, the phase angle was adjusted to nullify the changes in the real (Re) trace in response to the manually generated 10 femtofarad $(\mathrm{fF})$ calibration pulses. Vesicle capacitance $\left(C_{\mathrm{v}}\right)$ and $G_{\mathrm{p}}$ were calculated from the imaginary (Im) and Re part of the admittance traces as reported previously (Lollike and Lindau, 1999): $C_{\mathrm{v}}=\left[\left(\mathrm{Re}^{2}+\mathrm{Im}^{2}\right) / \mathrm{Im}\right] / \omega$, where $\omega$ is the angular frequency $(\omega=2 \pi f ; f$ is the sine-wave frequency, $1591 \mathrm{~Hz})$ and $G_{\mathrm{p}}=\left(\operatorname{Re}^{2}+\right.$ $\left.\mathrm{Im}^{2}\right) / \mathrm{Re}$. The fusion pore radius was estimated using the equation $G_{\mathrm{p}}=$ $\left(\pi r^{2}\right) /(\rho \lambda)$, where $r$ represents the fusion pore radius, $\rho$ is the estimated resistivity of saline $(100 \Omega \mathrm{cm})$, and $\lambda$ the estimated length of a gap junction channel (15 nm; Spruce et al., 1990). Vesicle diameter was calculated using a specific $C_{\mathrm{m}}$ of $8 \mathrm{fF} / \mu \mathrm{m}^{2}$. We used custom-made software (CellAn, Celica Biomedical) written for Matlab (Math Works) to analyze unitary exocytic events. Unless stated otherwise, chemicals were purchased from Sigma-Aldrich.

Electrophysiologic measurements of $\mathrm{I}_{h}$. $I_{\mathrm{h}}$ were measured in whole-cell voltage-clamp configuration. All experiments were performed at RT. Cells were placed in extracellular bath solution that contained the following: $113 \mathrm{~mm} \mathrm{NaCl}, 20 \mathrm{~mm} \mathrm{KCl}, 20 \mathrm{~mm}$ tetraethylammonium chloride, 2 
$\mathrm{mm} \mathrm{CaCl} 2,1 \mathrm{~mm} \mathrm{MgCl}, 10 \mathrm{~mm}$ 4-(2-hydrixyethyl)piperazine-1-ethanesulfonic acid, $10 \mathrm{~mm}$ D-glucose, $1 \mathrm{~mm}$ 4-amino-pyridine, $1 \mathrm{~mm} \mathrm{BaCl}_{2}, 1$ $\mathrm{mm} \mathrm{CdCl}_{2}$, and $0.001 \mathrm{~mm}$ tetrodotoxin with or without $100 \mu \mathrm{M} \mathrm{ZD7288.}$ The $\mathrm{pH}$ was adjusted to 7.3 with $\mathrm{NaOH}$. Patch pipettes were pulled from borosilicate glass capillaries (Harvard Apparatus) and heat polished to a tip resistance of $4-5 \mathrm{M} \Omega$. Pipette solution contained the following: $150 \mathrm{~mm} \mathrm{KCl}, 2 \mathrm{~mm} \mathrm{MgCl}_{2}, 10 \mathrm{~mm}$ 4-(2-hydroxyethyl)-1piperazineethanesulfonic acid, $2 \mathrm{~mm} \mathrm{Na} \mathrm{Na}_{2} \mathrm{ATP}$, and 2 mM EGTA. The $\mathrm{pH}$ was adjusted to 7.3 with $\mathrm{KOH}$. Voltage-clamp measurements were performed using a SWAM IIC amplifier (Celica Biomedical). The amplitude of $I_{\mathrm{h}}$ was calculated by subtracting the instantaneous current amplitude from the steady-state current at the end of the test voltage pulse to -120 $\mathrm{mV}$, and the density of $I_{\mathrm{h}}$ was calculated by dividing the current amplitude by the $C_{\mathrm{m}}$ for each given cell as explained by Kretschmannova et al. (2012). The voltage pulse duration was $30 \mathrm{~s}$.

Intracellular free $\mathrm{Ca}^{2+}$ measurements. Controls, HCN2-transfected cells, and ZD7288-treated cells were loaded with $2 \mu \mathrm{M}$ Fluo-4 AM (Invitrogen) for $30 \mathrm{~min}$ at $37^{\circ} \mathrm{C}$ and washed with the extracellular solution for $30 \mathrm{~min}$ at $37^{\circ} \mathrm{C}$ in the presence or in the absence of ZD7288. Imaging was performed with a confocal microscope (Zeiss LSM 780) with a $40 \times, 1.3$ numerical aperture objective (Zeiss Plan-Apochromat). An Ar-ion laser was used to excite Fluo- 4 in combination with a bandpass emission filter (505-530 nm). Fluo-4 fluorescence, reporting changes in $\left[\mathrm{Ca}^{2+}\right]_{\mathrm{i}}$, was measured in a region of interest covering the entire cell image. All images were taken with the identical laser power and detector gain settings. The fluorescence intensity change was defined as $\Delta F / F_{0}=\left(F_{(\mathrm{t})}-F_{0}\right) / F_{0}$, expressed as a percentage. $F_{0}$ is the average nonstimulated fluorescence intensity of 10 frames with the lowest intensity of fluorescence. $F_{(t)}$ is the fluorescence intensity at given time.

Data analysis. All statistics were performed using Sigma Plot. All results are presented as means \pm SEM. Statistical significance was evaluated using the Student's $t$ test or ANOVA with Holm-Sidak post hoc test for normally distributed data and the Mann-Whitney test or ANOVA on ranks with Dunn's post hoc test for non-normally distributed data $\left({ }^{*} p<\right.$ $0.05,{ }^{* *} p<0.01$, and ${ }^{* * *} p<0.001$.

\section{Results}

Our previous results show that an increase in intracellular cAMP significantly affects secretory activity in cultured pituitary lactotrophs (Calejo et al., 2013). Here we investigated whether HCN channels mediate the mechanism by which cAMP affects exocytosis.

\section{The HCN2 isoform is present in lactotrophs}

We used the Western blot technique to test whether HCN2 is present in the pituitary (Fig. 1a). In the total lysate, we detected a weak $95 \mathrm{kDa}$ band. Due to the apparent low expression of HCN2 at the protein level, we next performed quantitative real-time PCR specifically from lactotroph lysates (Fig. $1 b$ ). For this, we collected cell lysates from $>95 \%$ pure primary lactotroph cultures, as determined by labeling the cells with antibodies against PRL (Fig. 1c) and counting the fluorescent cells in cell cultures obtained from three independent isolations. In pituitary lactotrophs, the quantity of HCN2 mRNA transcripts was $0.5 \%$, compared with the mRNA of the housekeeping gene, $\beta$-actin (Fig. 1b).

We then used immunocytochemical labeling of cultured lactotrophs with anti-PRL and anti-HCN2 antibodies in combination with confocal microscopy (Fig. 1c). We first assessed the proportion of PRL-containing vesicles near the plasma membrane (Fig. 1ci). The colocalization of PRL and of the plasma membrane dye DiD fluorescent signals was $61 \pm 5 \%$, indicating that a large proportion of PRL-containing vesicles are located near the plasma membrane (Fig. 1civ), as reported previously (Jorgacevski et al., 2010). Similarly, we determined the proportion of HCN2 in the plasma membrane. Here, the colocalization a

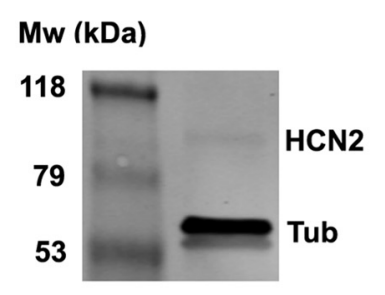

C
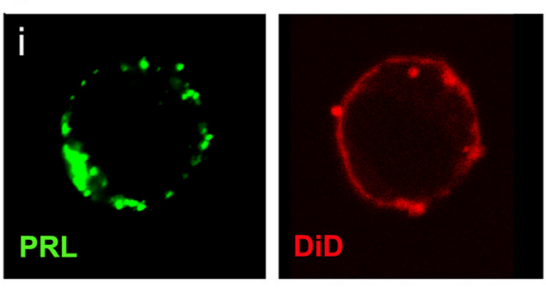

b
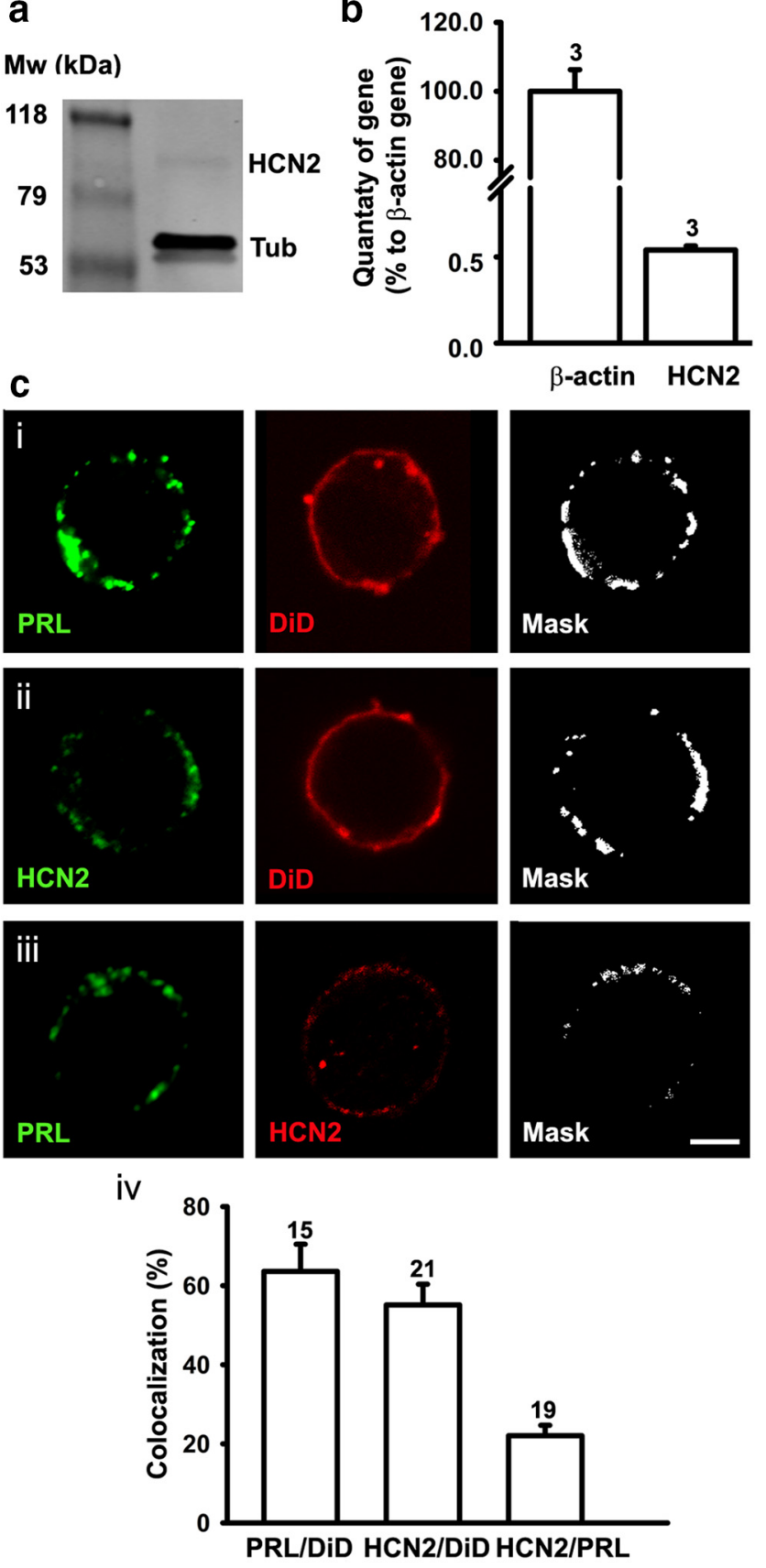

Figure 1. Augmentation of HCN2 channel isoform, which is present in the plasma membrane and in vesicles of lactotrophs, affects membrane conductance. $\boldsymbol{a}$, Western blot of the lysate of the whole pituitary gland showing a weak band corresponding to the HCN2 isoform and a stronger (double) band corresponding to tubulin. $\boldsymbol{b}$, In isolated lactotrophs, quantitative real-time $P C R$ revealed that the relative expression of $H C N 2$ mRNA in comparison with $\beta$-actin mRNA is $0.54 \pm 0.02 \%$. ci, Representative confocal image of a lactotroph that was exposed to the plasma membrane marker DiD, fixed and labeled with anti-PRL antibodies (PRL). The mask shows the colocalization between PRL and DiD. cii, Representative confocal image of a lactotroph that was exposed to DiD, fixed, and labeled with anti-HCN2 antibodies (HCN2). The mask shows the colocalization between HCN2 and DiD. ciii, Representative confocal image of a fixed lactotroph, labeled with anti-HCN2 antibodies (HCN2) and with anti-PRL antibodies (PRL). The mask shows the colocalization between HCN2 and PRL. Scale bar, $3 \mu \mathrm{m}$. civ, The mean colocalization of DiD and PRL was $64 \pm 7 \%$ (colocalized pixels vs PRL fluorescence pixels), the colocalization of DiD and HCN2 fluorescence was $55 \pm 5 \%$ (colocalized pixels vs HCN2 fluorescence pixels), and the colocalization of PRL and HCN2 fluorescence was $22 \pm 3 \%$ (colocalized pixels vs HCN2 fluorescence pixels). Numbers above error bars denote the number of analyzed cells from two different isolations. Values are means \pm SEM. 
a
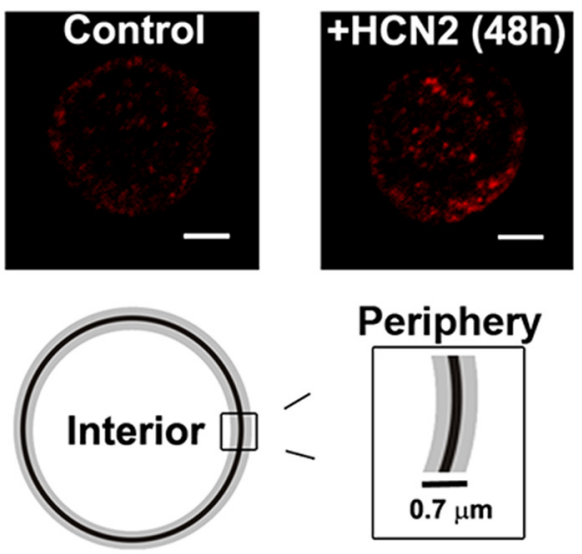

b

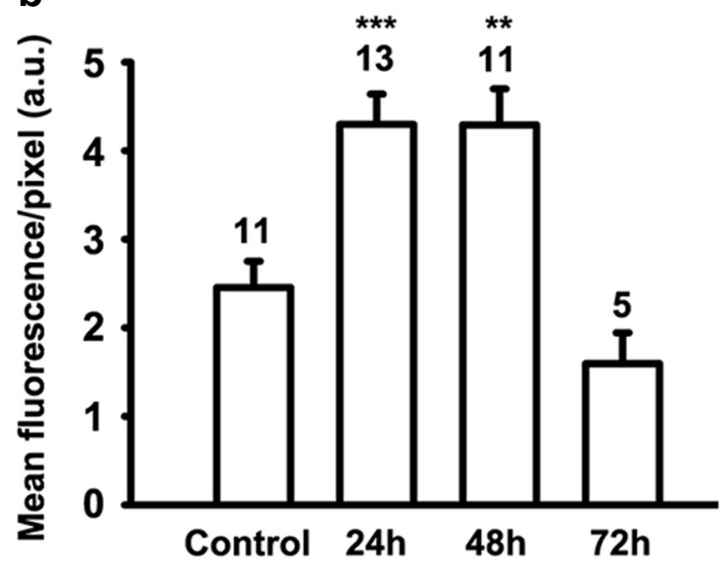

C

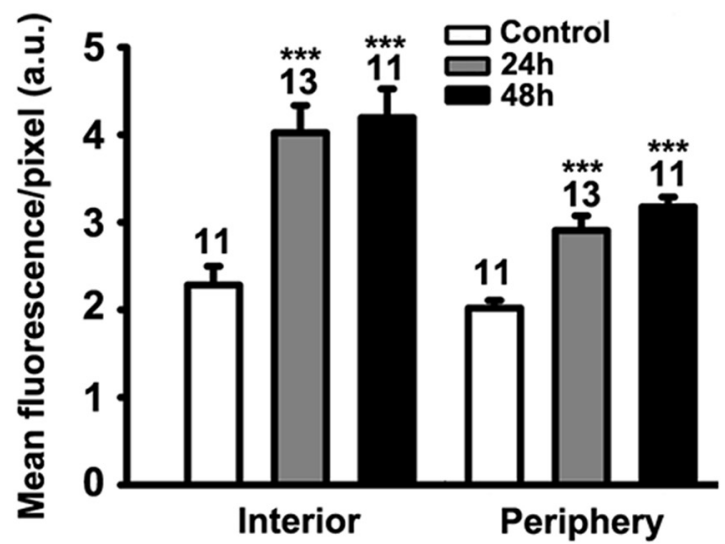

di
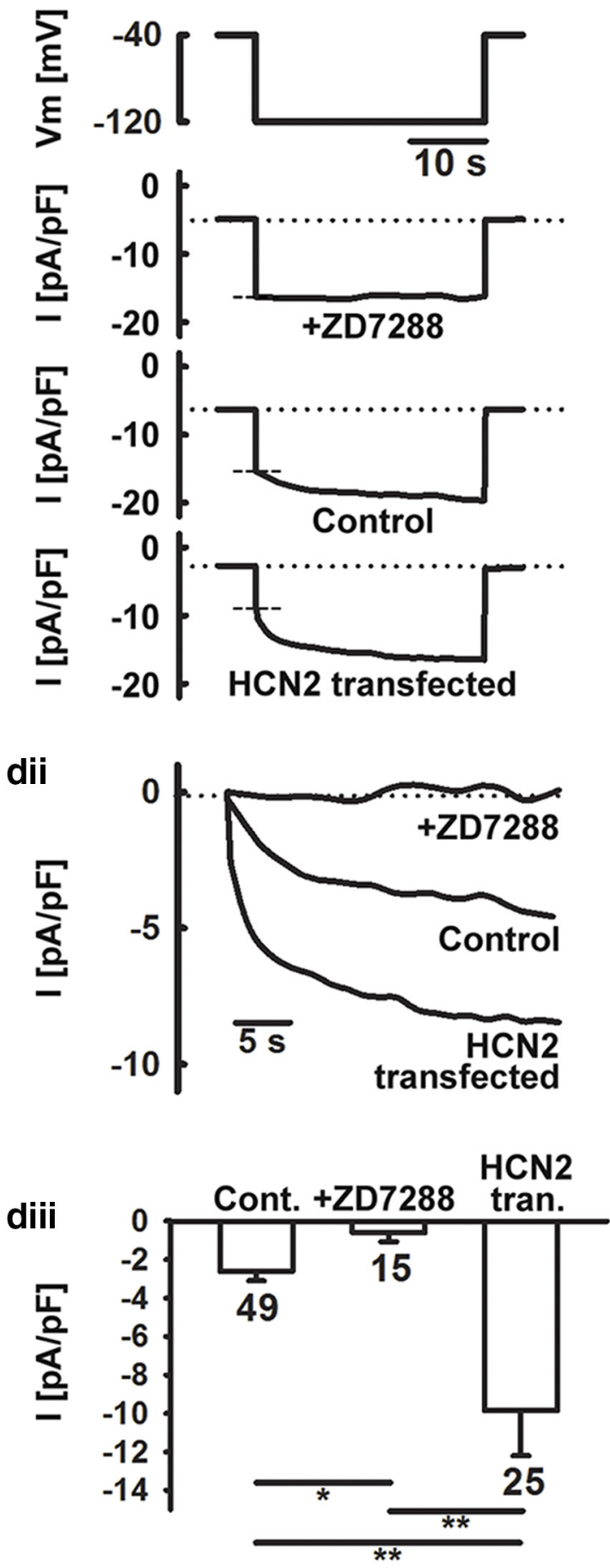

Figure 2. Overexpression of the HCN2 isoform augments the presence of HCN2 in lactotrophs. $\boldsymbol{a}$, Representative confocal images of a nontransfected lactotroph and a lactotroph $48 \mathrm{~h}$ after transfection with pDNA encoding HCN2. Both lactotrophs were fixed and immunolabeled with anti-HCN2 antibodies. Scale bars, $3 \mu \mathrm{m}$. We analyzed the intensity of fluorescence, as depicted on the diagram in the lower part of the panel. The fluorescence intensity was separated into two areas: the rim representing the plasma membrane (depicted in gray) and the cell interior, which is located centrally to the rim. The thickness of the rim representing the plasma membrane was $0.7 \mu \mathrm{m}$, which corresponds to the mean diameter of two lactotroph vesicles (Zorec et al., 1991 ; Angleson et al., 1999). $\boldsymbol{b}$, The mean fluorescence, measured in confocal micrographs of fixed HCN2-labeled lactotrophs. The mean fluorescence of HCN2-labeled lactotrophs transfected with HCN2 plasmids increased $24 \mathrm{~h}$ after transfection $(p<0.001)$ and remained elevated $48 \mathrm{~h}$ after transfection $(p=0.009)$. However, $72 \mathrm{~h}$ after transfection, the mean fluorescence of HCN2-transfected cells decreased to basal levels ( $p=0.1 \mathrm{vs} \mathrm{control).} c$, Separate analysis of the mean fluorescence in the interior region of the cell and in the plasma membrane region showed that both regions follow a similar trend to the mean fluorescence of whole cells, analyzed in $\boldsymbol{b}$. $\boldsymbol{d}$, Voltage-clamp measurements of $/ \mathrm{h}$ in control, ZD7288-treated, and HCN2-overexpressed lactotrophs. di, The representative current $I_{\mathrm{h}}$ density recordings in response to a $30 \mathrm{~s}$ hyperpolarizing voltage pulse (to $-120 \mathrm{mV}$ ). The dotted line depicts baseline current density and the dashed line depicts instantaneous current density amplitude elicited by a voltage step of $-80 \mathrm{mV}$. dii, Representative HCN currents for ZD7288-treated, control, and HCN2-transfected cells. diii, ZD7288 treatment significantly reduced $I_{\mathrm{h}}$ current density, while transfection with HCN2 $\mathrm{pDNA}$ strongly enhanced $I_{\mathrm{h}}$ current density. The numbers above the error bars indicate the number of cells analyzed. Values are means \pm SEM. ${ }^{*} p<$ $0.05,{ }^{* *} p<0.01,{ }^{* * *} p<0.001$. 
a
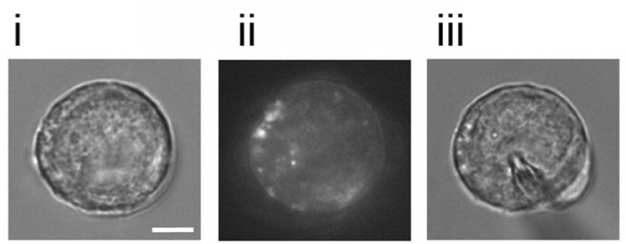

b

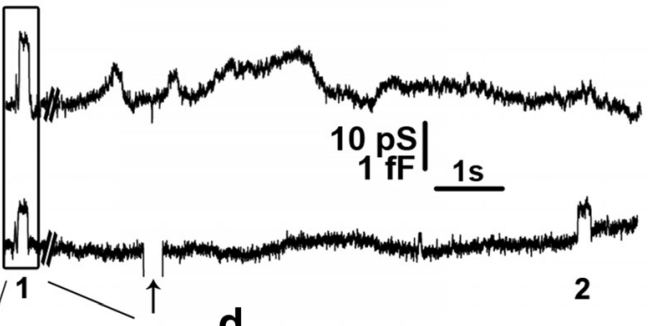

C

d

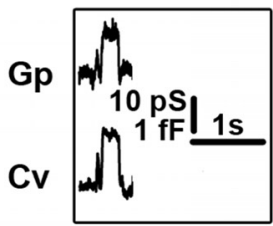

$\operatorname{Re}$

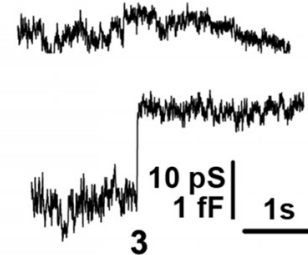

e

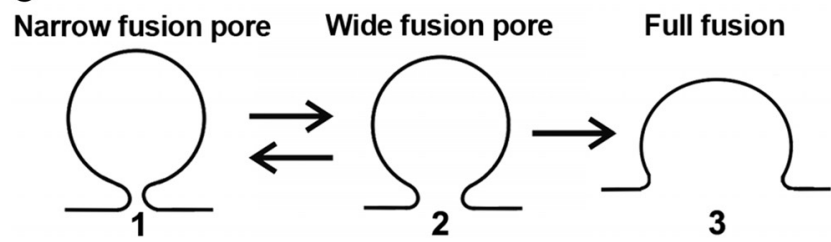

Figure 3. Cell-attached $C_{m}$ measurements on transfected lactotrophs confirm the presence of transient and full-fusion exocytic events. $\boldsymbol{a}$, Lactotrophs cotransfected with HCN2 pDNA and EGFP pDNA were used for the $C_{m}$ measurements in the cell-attached configuration. ai-aiii, All measurements were performed only on lactotrophs exhibiting EGFP fluorescence, as shown for the same cell under transmitted light ( $\boldsymbol{a} \boldsymbol{i})$, under epifluorescence (aii), and during the measurement (aiii). Scale bar, $3 \mu \mathrm{m}$. $\boldsymbol{b}$, An epoch from the representative recording showing reversible steps in the Im part of the admittance trace. Reversible events in Im, which likely represent transient exocytic events, either exhibited projections (1) to the Re part of the admittance trace or not (2). The arrow points to the calibration pulse in $I m$, which was triggered manually to ensure the correct phase angle settings. c, We calculated $C_{v}$ and $G_{p}$ for all reversible events with projections (see Materials and Methods). $\boldsymbol{d}$, A representative example of irreversible upward steps in the Im trace and the corresponding Re trace (3), which likely denotes a full-fusion exocytic event. $\boldsymbol{e}$, A scheme of the stages that a vesicle must pass to completely fuse with the plasma membrane; from narrow fusion pore formation (1), to widening of the fusion pore (2), and finally to full fusion of the vesicle membrane and the plasma membrane (3).

of HCN2 with the plasma membrane DiD fluorescent signals was $55 \pm 5 \%$, indicating that approximately half of the HCN2containing channels are located in the plasma membrane or nearby, considering the optical limits of the confocal microscope (Fig. 1cii). In neurons, HCN channels are also located in the cytoplasmic vesicular structures (Noam et al., 2010). To check whether HCN2-containing channels are colocalized with PRLcontaining vesicles, we immunolabeled lactotrophs with antibodies against HCN2 and PRL (Fig. 1ciii). The mean colocalization of the fluorescence signals of these two markers was $22 \pm 3 \%$ (Fig. 1civ), indicating that $\mathrm{HCN} 2$ channels are located either on or near approximately one-fifth of PRL-containing vesicles.

The expression of HCN2-containing channels in lactotrophs can be augmented

We next augmented the expression of HCN2 in lactotrophs by transfection with pDNA encoding HCN2. Cotransfection was performed using equal amounts of pDNA encoding $\mathrm{HCN} 2$ and
pEGFP (see Materials and Methods). The latter was used to identify transfected fluorescent green cells. To determine the extent of amplification of HCN2 expression, we used antibodies against HCN2 to immunolabel nontransfected (control) lactotrophs and lactotrophs 24, 48, and $72 \mathrm{~h}$ after transfection (Fig. 2a).

The mean fluorescence intensity of $\mathrm{HCN} 2$, determined in the region of the whole-cell image, was $2.6 \pm 0.3$ a.u. ( $n=11$ cells $)$ in controls and significantly increased $24 \mathrm{~h}$ after the transfection to $4.3 \pm 0.3$ a.u. $(n=13$ cells; $p<0.001 ;$ Fig. $2 b)$. This increase was still observed $48 \mathrm{~h}$ after transfection, $4.3 \pm 0.4$ a.u. ( $n=11$ cells, $p=0.009$; Fig. $2 b$ ), whereas $72 \mathrm{~h}$ after transfection the mean fluorescence decreased below the control values to $1.6 \pm 0.4$ a.u. ( $n=5$ cells, $p=0.1$ ). To determine whether the observed increase in fluorescent signals (after 24 and $48 \mathrm{~h}$ ) occurred proportionally in the plasma membrane and in the cell interior, we performed a separate analysis of the fluorescence intensity of the plasma membrane region and of the cell interior region, as shown in the scheme in Figure 2a. The results show that the increase in HCN2 fluorescence was similar in both regions, at the plasma membrane and in the cell interior $(p<0.001$, compared with controls; Fig. 2c), and indicate that the expression of $\mathrm{HCN} 2$ is augmented in localities close to the fusing vesicles.

\section{Augmentation of HCN2 expression and inhibition of $\mathrm{HCN}$ channels with ZD7288 affect membrane conductance} To quantify the augmentation of HCN2 expression and translocation of HCN2 channels to the plasma membrane, we performed whole-cell voltage-clamp measurements to record $I_{\mathrm{h}}$, which are mediated by HCN channels (Gauss et al., 1998; Kretschmannova et al., 2012; Fig. 2d). The mean current density in controls was $2.6 \pm 0.5 \mathrm{pA} / \mathrm{pF}$ ( $n=49$ cells $)$ and was strongly attenuated in cells that were treated by a selective $\mathrm{HCN}$ channel blocker ZD7288 (0.6 $\pm 0.4 \mathrm{pA} / \mathrm{pF}, n=15$ cells, $p<0.05$; Fig. 2diii). On the other hand, transfection of lactotrophs with HCN2 pDNA enhanced $I_{\mathrm{h}}$ density to $9.9 \pm 2.3 \mathrm{pA} / \mathrm{pF}$ ( $n=25$ cells, $p<$ 0.01; Fig. 2diii). It can be concluded that the augmentation of $\mathrm{HCN} 2$ expression significantly increases the conductance upon hyperpolarization of the plasma membrane $(\leq 4 \times)$ and that blockade of HCN channels with ZD7288 practically abolishes $I_{\mathrm{h}}$. Furthermore, these results confirm that, after transfection, HCN2 pDNA is successfully translated and that fully functional $\mathrm{HCN}$ channels with $\mathrm{HCN} 2$ isoform are inserted into the plasma membrane. Assuming there are no changes in HCN channel gating and conductance, the increase in current density suggests a fourfold increase in functional HCN channels in transfected cells (twice the increase estimated by immunocytochemistry).

\section{Transient and full-fusion exocytic events are present in} lactotrophs overexpressing $\mathrm{HCN} 2$

We have previously shown that the increase in intracellular cAMP affects unitary exocytic events by stabilizing transient fusion pores with relatively wide fusion pore diameters and with prolonged fusion pore dwell times (Calejo et al., 2013). Here, we used a cell-attached patch-clamp technique to monitor discrete changes in $C_{\mathrm{m}}$, with sufficient resolution to detect unitary fusions of vesicles with the plasma membrane in lactotrophs overexpressing HCN2, as described by Rituper et al. (2013). $C_{\mathrm{m}}$ measurements were performed on EGFP-positive (fluorescent) lactotrophs as shown in Figure $3 a$. We observed in $C_{\mathrm{m}}$ discrete reversible steps that depict transient fusion pore openings of transient exocytosis (Fig. $3 b, 1,2$ ) and irreversible upward steps that represent full-fusion unitary exocytic events (Fig. 3d, 3; Vardjan et al., 2007; Jorgacevski et al., 2008). Transient exocytic 


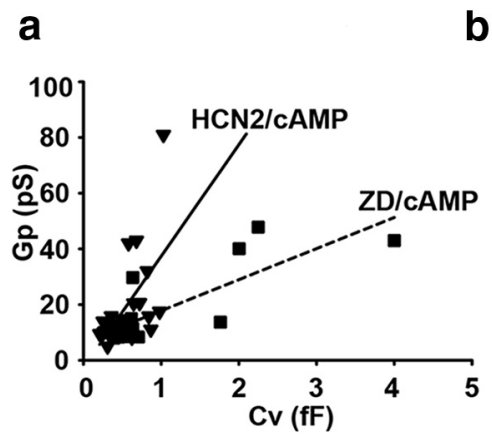

Figure 4. The $H C N 2$ channel isoform increases $G_{p} \cdot \boldsymbol{a}$, Scatter plot diagram of $G_{\mathrm{p}}$ versus $C_{v}$ of reversible events in cells transfected with pDNA of the HCN2 isoform and stimulated with cAMP (full triangles) and of reversible events in cells treated with ZD7288 and stimulated with cAMP (full squares). The respective data points were best fitted with two linear regressions of the form $y\left(G_{\mathrm{p}}\right)=[20$ $\left.\mathrm{pS} / \mathrm{fF} \times x\left(C_{\mathrm{v}}\right)\right]+3 \mathrm{pS} / \mathrm{fF}(\mathrm{HCN} 2 / \mathrm{CAMP}$, solid line, $r=0.6)$ and $y\left(G_{\mathrm{p}}\right)=\left[6 \mathrm{pS} / \mathrm{fF} \times x\left(C_{\mathrm{v}}\right)\right]+7 \mathrm{pS} / \mathrm{fF}(\mathrm{ZD} 7288 / \mathrm{cAMP}$, dashed line, $r=0.8, p=0.05)$. Significance was tested using one-way ANCOVA for two independent samples. $\boldsymbol{b}$, The relationship between the percentage of projected reversible events and the slope of the regression line between $G_{p}$ and $C_{v}$, for each of the tested conditions. The dotted vertical line denotes the percentage of transient exocytic events that exhibited measurable fusion pores of transient events under spontaneous conditions (25\%; see Materials and Methods). Transfection of HCN2 with pDNA resulted in a decreased percentage of measurable fusion pores of transient events (wider fusion pores). Meanwhile, treatment with ZD7288 resulted in an increased percentage of measurable fusion pores (narrower fusion pores).

events, observed in the Im trace of the admittance signal, were often projected to the Re part of the admittance signal. These events indicate the presence of a narrow fusion pore (Fig. 3b, 1; Lollike and Lindau, 1999) and were used to calculate the $G_{p}$, which is proportional to the fusion pore diameter (Fig. $3 c$; see Materials and Methods). We calculated the fraction of narrow fusion pore events as the percentage of transient exocytic events with projections versus all transient exocytic events. In addition, we calculated the $C_{\mathrm{v}}$, which was used to estimate the surface area of vesicles and, by considering that vesicles are spheres, their diameter (see Materials and Methods).

\section{HCN2 modulates fusion pore properties in lactotrophs}

Previously, we observed that the $G_{\mathrm{p}}$ in vesicles that are engaged in transient exocytosis depends on the $C_{\mathrm{v}}$ (Jorgacevski et al., 2010). In transient exocytic events the $G_{\mathrm{p}}-C_{\mathrm{v}}$ relationship represents a measure of efficient vesicular release. If we consider that other limiting factors (e.g., vesicular matrix in large dense core vesicles) are unchanged, a higher $G_{\mathrm{p}}-C_{\mathrm{v}}$ relationship indicates a higher rate of vesicular release. To assess whether HCN channels affect the $G_{\mathrm{p}}-C_{\mathrm{v}}$ relationship, we analyzed transient exocytic events, which appear in the Im trace and exhibit a projection to the Re trace, to calculate $G_{\mathrm{p}}$ and $C_{\mathrm{v}}$ (Fig. $3 c$ ). We first compared how the overexpression of HCN2 and the inhibition of HCN channels (by ZD7288) under cAMP-stimulated conditions affect the $G_{\mathrm{p}}-C_{\mathrm{v}}$ relationship (Fig. 4a). The respective datasets were best fitted with linear regression lines with the following slopes: $20 \mathrm{pS} / \mathrm{fF}$ for HCN2-transfected lactotrophs and $6 \mathrm{pS} / \mathrm{fF}$ for lactotrophs treated with ZD7288 (Fig. 4a). These results indicate that HCN channels regulate the transitions from narrow to wider fusion pore states. However, the $G_{\mathrm{p}}-C_{\mathrm{v}}$ relationship can only be determined for the fusion events that exhibit relatively narrow fusion pores (with a projection between the Im and the Re trace), which corresponds to $\sim 25 \%$ of all events in controls (Fig. $4 b$ ). The treatment with ZD7288 increased the proportion of narrow fusion pores to $\sim 38 \%$ and the addition of cAMP further increased it to $\sim 55 \%$. On the other hand, the overexpression of HCN2 decreased the proportion of narrow fusion pores to $\sim 17 \%$, which decreased further to $\sim 8 \%$ after the addition of cAMP.
These results support the conclusion, that $\mathrm{HCN}$ channels are involved in the modulation of the fusion pore diameter. Our next aim was to analyze the occurrence of transient and full-fusion exocytic events, to see whether HCN channels also affect exocytic activity.

\section{HCN channels modulate the frequency of exocytic events in lactotrophs}

To evaluate whether the overexpression of HCN2 modulates exocytic activity, we monitored changes in $C_{\mathrm{m}}$ in lactotrophs expressing only the native $\mathrm{HCN} 2$ isoform (control), and in lactotrophs cotransfected with pDNA of HCN2 and pEGFP (HCN2). Possible effect(s) of EGFP on exocytic activity were excluded in a separate set of experiments (EGFP). The role of HCN2 channels was further validated by selectively blocking HCN channels by ZD7288. Last, we assessed potential effects of elevated cAMP levels (the addition of $10 \mathrm{~mm} \mathrm{dbcAMP}$ ) on exocytic activity of lactotrophs that were either overexpressing $\mathrm{HCN} 2$ or where HCN activity was blocked with ZD7288.

We analyzed the occurrence of transient and full-fusion exocytic events by determining the frequency of reversible (Fig. $5 a$ ) and irreversible unitary discreet steps in $C_{\mathrm{m}}$ (events; Fig. $5 b$ ). The frequency of reversible and irreversible events in pEGFPtransfected lactotrophs was identical to that of controls: $0.05 \pm$ 0.01 events/s $(n=8$ patches $)$ and $0.06 \pm 0.01$ events/s $(n=16$ patches) for reversible events and $0.005 \pm 0.001$ events/s $(n=8$ patches) and $0.005 \pm 0.001$ events/s ( $n=16$ patches $)$ for irreversible events, respectively. These results confirm that the expression of EGFP does not significantly affect the frequency of unitary exocytic events in lactotrophs. On the other hand, overexpression of HCN2 significantly decreased the frequency of transient fusion events to $0.02 \pm 0.01$ events/s $(n=16$ patches; $p=0.009)$. However, their frequency increased after stimulation with dbcAMP $(0.04 \pm 0.001$ events/s; $n=16$ patches; $p=0.04)$, approaching the values in nontransfected (and nonstimulated) lactotrophs (Fig. 5c).

The increase in the frequency of transient exocytic events after the stimulation with dbcAMP in HCN2-transfected lactotrophs is in line with the trend observed in CAMP-stimulated nontransfected lactotrophs (Calejo et al., 2013). However, in the aforementioned study, the addition of dbcAMP decreased the frequency of full-fusion exocytic events in nontransfected lactotrophs. This was not the case in HCN2-transfected lactotrophs, where the addition of dbcAMP increased the frequency of fullfusion exocytic events from $0.002 \pm 0.001$ events/s before stimulation to $0.006 \pm 0.001$ events $/ \mathrm{s}(n=16$ patches; $p=0.04)$ after stimulation (Fig. $5 d$ ).

The treatment of lactotrophs with ZD7288 resulted in a reduced frequency of transient exocytic events $(0.04 \pm 0.01$ events/s; $n=6$ patches; $p<0.001$ ) compared with controls (Fig. $5 e)$. The addition of dbcAMP further decreased the frequency of transient exocytic events to $0.01 \pm 0.01$ events/s $(n=6$ patches; $p<0.001$; Fig. $5 e$ ). The same tendency (although not statistically significant) was observed in the frequency of full-fusion exocytic events, which decreased to $0.004 \pm 0.001$ events/s ( $n=6$ patches; 
ZD) and to $0.002 \pm 0.001$ events/s $(n=6$ patches; after the addition of cAMP; Fig. $5 f$ ).

These data show that HCN channels can influence exocytic activity.

\section{$\mathrm{HCN}$ channels affect $\left[\mathrm{Ca}^{2+}\right]_{\mathrm{i}}$ levels in lactotrophs}

To test whether the observed changes in exocytic activity in HCN2-transfected and ZD7288-treated cells are related to the changes in $\left[\mathrm{Ca}^{2+}\right]_{\mathrm{i}}$, we performed calcium measurements with a calcium indicator, Fluo-4 AM (Fig. 6). The addition of dbcAMP did not significantly affect $\left[\mathrm{Ca}^{2+}\right]_{\mathrm{i}}$ levels in cells overexpressing HCN2 (Fig. 6a,c). In contrast, the addition of dbcAMP to ZD7288-treated cells significantly reduced $\left[\mathrm{Ca}^{2+}\right]_{\mathrm{i}}$ (Fig. $\left.6 b, c\right)$. Moreover, the mean Fluo-4 fluorescence was measured before the addition of $\mathrm{db}$ cAMP in controls, in HCN2-transfected cells, and in ZD7288-treated cells. The mean basal $\left[\mathrm{Ca}^{2+}\right]_{\mathrm{i}}$, which was significantly higher in controls compared with HCN2-transfected cells and ZD7288treated cells, respectively (Fig. $6 d$ ), was then related to the frequency of reversible and irreversible exocytic events in all three experimental groups. Data pairs were fitted with linear regression lines that had Pearson's coefficient $(r)>0.99$ for both fits, indicating a strong correlation between these two parameters (Fig. 6e).

These results indicate the involvement of $\mathrm{HCN}$ channels in the regulation of $\left[\mathrm{Ca}^{2+}\right]_{\mathrm{i}}$ and consequently indirectly also in exocytic activity in pituitary lactotrophs. However, some of the HCNmediated effects, such as those involving cAMP-mediated fusion pore widening, are believed to directly affect the fusion pore, since cAMP did not affect $\left[\mathrm{Ca}^{2+}\right]_{\mathrm{i}}$ in $\mathrm{HCN} 2$-transfected cells, while an increase in $\left[\mathrm{Ca}^{2+}\right]_{i}$ is required for fusion pore widening (Vardjan et al., 2007).

\section{Discussion}

The results of this study show that regulation of exocytic fusion pore in lactotrophs involves HCN channels, which are gated by cAMP. HCN channels are located either in the vesicular membrane or in the plasma membrane next to the fused vesicle, which affects local membrane curvature and consequently dilates fusion pore as described by Kabaso and coworkers (Kabaso et al., 2012). Based on this model and on the results showing that electrostatic interactions determine fusion pore properties (Calejo et al., 2012), we suggest that fusion pore geometry is affected by local changes in cation concentration. Changes in cAMP levels affect HCN channel conductance and thus can alter local cation concentration during hyperpolarization and during early stages of depolarization (Biel et al., 2002). This mechanism, regulating transient (kiss-and-run) exocytosis, may play a more general role in the nervous system. 0.001 .
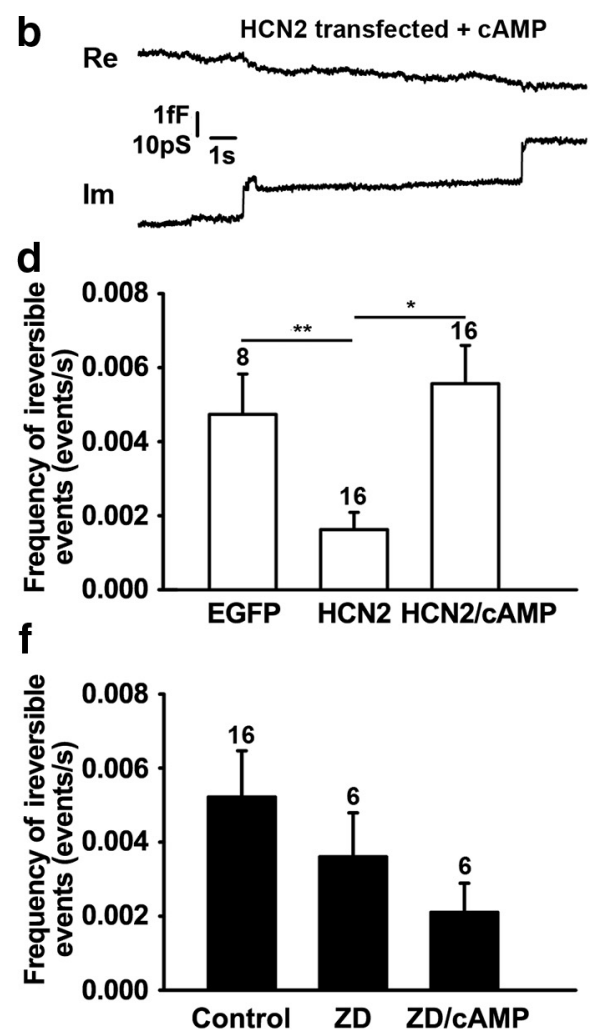

Figure 5. The HCN2 channel isoform modulates the frequency of exocytic events in lactotrophs. $\boldsymbol{a}, \boldsymbol{b}$, Two epochs of the representative electrophysiologic recording, which was made on a lactotroph transfected with pDNA of HCN2 and stimulated with -transfected cells with dbCAMP, the mean frequency of reversible events increased to $0.04+0.01$ events/s. $d$ The mean frequency of irreversible upward events in EGFP-transfected cells was $0.005 \pm 0.001$ events/s, significantly more than in HCN2作 (with ZD7288 and CAMP).f, A similar trend was observed in the frequencies of irreversible upward events: $0.005 \pm$ Values are means \pm SEM. The numbers above the error bars indicate the number of patches. ${ }^{*} p<0.05,{ }^{* *} p<0.01,{ }^{* * *} p<$

Our results unambiguously confirm that HCN channels, and the HCN2 isoform specifically, are present in isolated rat lactotrophs (Fig. 1). We focused on the HCN2 isoform for three reasons: (1) this isoform is the most ubiquitously distributed isoform in the brain (Shi et al., 1999); (2) mRNA transcripts of this isoform are the most abundant in the pituitary gland (Kretschmannova et al., 2012); and (3) HCN2 is highly sensitive to cAMP (Kaupp and Seifert, 2001). Using Western blotting, we confirmed the native expression of HCN2 in the pituitary gland (Fig. 1c). The overall amount of HCN2 mRNA transcript in lactotrophs, which was $<1 \%$ of the mRNA transcript of $\beta$-actin (Fig. $1 d$ ), is in agreement with previous studies on other secretory cells, where very low amounts of the transcripts were detected (El-Kholy et al., 2007). Similarly, the subcellular localization of $\mathrm{HCN}$ channels in lactotrophs is consistent with previous findings (Noam et al., 2010; Fig. 1 ). It is therefore not surprising that, in our experiments, $\sim 55 \%$ of $\mathrm{HCN} 2$ is located in the plasma membrane of lactotrophs and $~ 22 \%$ are either on or near PRL-containing vesicles (Fig. 1civ). The remaining $\sim 23 \%$ that are not accounted for are most likely localized in other subcellular organelles, such as constitutive vesicles, endosomes, endoplasmic reticulum, and the Golgi apparatus. 

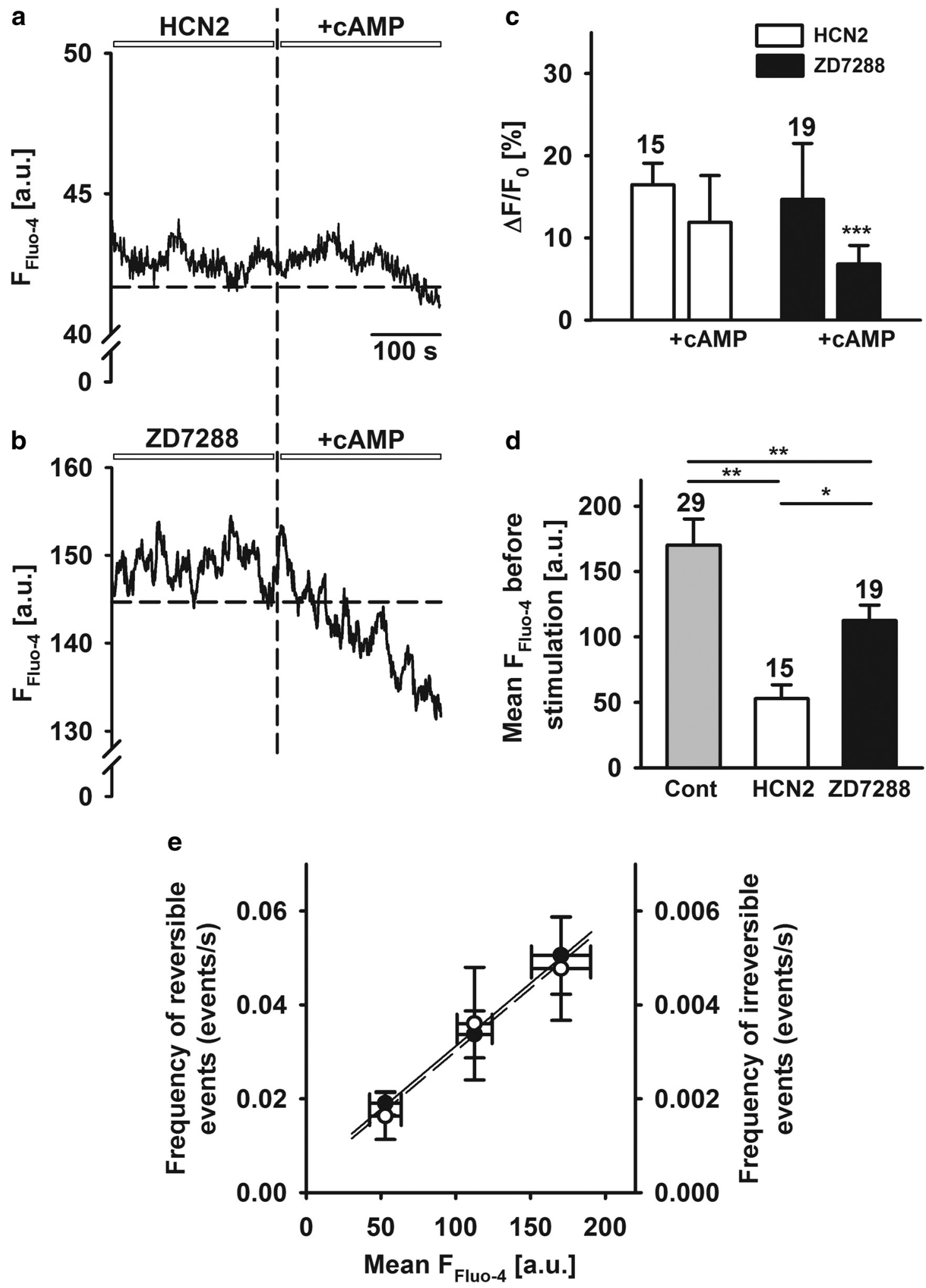

Figure 6. HCN channels affect $\left[\mathrm{Ca}^{2+}\right]_{\mathrm{i}}$ levels in lactotrophs. $\boldsymbol{a}, \boldsymbol{b}$, Fluo-4 fluorescence intensity $\left(F_{\text {Fluo-4 }}\right)$ changes in the representative HCN2-transfected cell $(\boldsymbol{a})$ and in the representative ZD7288-treated cell ( $\boldsymbol{b}$ ) before and after the addition of $10 \mathrm{~mm}$ dbcAMP ( + CAMP). Changes in the Fluo-4 fluorescence are proportional to changes in $\left[\mathrm{Ca}^{2+}\right]_{\mathrm{i}}$. The horizontal dashed line represents $F_{0}$ (see Materials and Methods). The vertical dashed line denotes the time point of dbcAMP addition. $c$, The addition of dbcAMP did not affect [ $\left.\mathrm{Ca}^{2+}\right]_{\mathrm{i}}$ levels in $\mathrm{HCN2}$-transfected cells. On the other hand, the addition of dbcAMP significantly decreased $\left[\mathrm{Ca}^{2+}\right]_{i}$ levels in ZD7288-treated cells. The significance was tested with paired Student's $t$ test. $\boldsymbol{d}$, The mean Fluo-4 fluorescence before the addition of dbcAMP was significantly higher in controls compared with HCN2-transfected cells and ZD7288-treated cells, respectively. $\boldsymbol{e}$, The correlation between the resting mean Fluo-4 fluorescence and the mean frequency of reversible (filled circles) and irreversible (empty circles) exocytic events. Fitted to the data are two regression lines of the form $y$ (frequency of irreversible events $)=\left[2.7 \times 10^{-5} \times x\left(\right.\right.$ mean $\left.\left.F_{\text {fluo }}\right)\right]+\left[3.0 \times 10^{-4}(r>0.99)\right]$ and $y$ (frequency of reversible events $)=\left[3.0 \times 10^{-4} \times x\left(\right.\right.$ mean $\left.\left.F_{\text {fluo }}\right)\right]+\left[4.4 \times 10^{-3}\right](r>0.99)$. Values are means \pm SEM. The numbers above the error bars indicate the number of cells analyzed. ${ }^{*} p<0.05$, ${ }^{* *} p<0.01,{ }^{* * *} p<0.001$. 
The surface expression of HCN2 and HCN4 isoforms is maintained by recycling endosomes, which store $\mathrm{HCN}$ channels (Hardel et al., 2008). The abundance of HCN channels on the cell surface therefore depends on secretory and endocytic pathways. Is the opposite true as well? Do HCN channels affect the stages of vesicular fusion with the plasma membrane that involve the fusion pore? The fact that, following the transfection with the plasmid-encoding HCN2 isoform, we observed an equivalent increase of HCN2 isoform in the plasma membrane and in the cell interior, is an indication that the $24-48 \mathrm{~h}$ time window was sufficient for the synthesis, the traffic to the plasma membrane, and internalization in the plasma membrane to reach a balance (Fig. $2 c$ ). This observation was confirmed by voltage-clamp measurements of HCN-specific $I_{\mathrm{h}}$ (Fig. $2 d$ ). Measurements of $I_{\mathrm{h}}$ during the 24-48 h window after transfection with HCN2 pDNA revealed $\sim 4$-fold increase in $I_{\mathrm{h}}$ density, indicating increased numbers of functional HCN2 channels in the plasma membrane. This experiment also confirms that the increase in the HCN2 immunofluorescence signal reflects the increase in the quantity of $\mathrm{HCN}$ channels.

cAMP has been shown to affect the release of PRL from lactotrophs, facilitating pace-making activity and voltage-gated calcium influx by predominantly PKA-independent and Epacindependent mechanisms (Gonzalez-Iglesias et al., 2006b). This makes HCN channels very likely candidates to be involved directly in the regulation of exocytosis. Our results support this notion, since both the overexpression of HCN2 and the inhibition of HCN channels by ZD7288 had pronounced effects on the properties and occurrence of unitary exocytic events (Figs. 4, 5). The latter effect is correlated to altered $\left[\mathrm{Ca}^{2+}\right]_{\mathrm{i}}$ levels (Fig. 6) and may indicate that HCN channels affect exocytotic activity indirectly via the modulation of $\left[\mathrm{Ca}^{2+}\right]_{\mathrm{i}}$. In contrast, the cAMPmediated fusion pore widening (Calejo et al., 2013; Fig. 4) is more likely due to a direct effect via $\mathrm{HCN}$ channels at the exocytotic apparatus, since cAMP did not affect $\left[\mathrm{Ca}^{2+}\right]_{\mathrm{i}}$ in $\mathrm{HCN} 2-$ transfected cells, while an increase in $\left[\mathrm{Ca}^{2+}\right]_{\mathrm{i}}$ is required for fusion pore widening (Vardjan et al., 2007).

Overexpression of $\mathrm{HCN} 2$ increased the inward cation current during hyperpolarization (Fig. $2 d$ ) and resulted in fusion pore openings with relatively wide fusion pores (Fig. 4). This effect was strengthened by the addition of cAMP, an activator of $\mathrm{HCN}$ channels. On the other hand, near complete blockage of $\mathrm{HCN}$ currents by ZD7288 resulted in the opening of a very narrow fusion pores (Fig. 2d). Fusion pores were even narrower if ZD7288-treated cells were stimulated with cAMP (Fig. 2b). This is likely due to the altered local cation concentrations, which affect fusion pore geometry via electrostatic interactions, as proposed by Kabaso et al. (2012). Moreover, cAMP induced markedly different effects in the presence or in the absence of ZD7288. While the addition of cAMP dilated fusion pores in the presence of normally conducting HCN channels, likely by stimulating additional influx of cations (although the mean $\left[\mathrm{Ca}^{2+}\right]_{\mathrm{i}}$ remained unchanged; Fig. $6 c$ ), it further narrowed fusion pores when the HCN channels were blocked. This effect is likely caused by the activation of sarco/endoplasmic reticulum $\mathrm{Ca}^{2+}$-ATPase (SERCA) in response to the elevated cAMP (Schmidt et al., 1999), which subsequently decreases $\left[\mathrm{Ca}^{2+}\right]_{\mathrm{i}}$, as demonstrated in Figure $6 c$.

It has recently been shown that vesicular calcium channels regulate exocytosis by facilitating calcium entry through the fusion pore. This generates microdomains of increased $\left[\mathrm{Ca}^{2+}\right]_{i}$ around the fused vesicles, which leads to the expansion of the fusion pore (Miklavc et al., 2011). Previous studies on lactotrophs showed a strong correlation between an increase in $\left[\mathrm{Ca}^{2+}\right]_{\mathrm{i}}$ and an increase exocytic activity (Vardjan et al., 2007; Jorgacevski et al., 2008). Although major physiologic implications of $\mathrm{Ca}^{2+}$ signaling through these channels remain unclear, overexpression of $\mathrm{HCN} 2$ should result in a local increase in $\left[\mathrm{Ca}^{2+}\right]_{\mathrm{i}}$, which would in turn increase the $\mathrm{Ca}^{2+}$-dependent fusion of vesicles. Interestingly, the mean $\left[\mathrm{Ca}^{2+}\right]_{i}$ was $\sim 3$-fold lower in the HCN2transfected cells (compared with controls; Fig. $6 d$ ), which correlates well with the observed $\sim 2.5$-fold reduction in the rate of exocytic activity (Fig. $5 c, d$ ). It is known that adenylyl cyclases (ACs) are intimately associated with sites of $\mathrm{Ca}^{2+}$ entry into the cell (Cooper et al., 1995). The local increase in $\left[\mathrm{Ca}^{2+}\right]_{\mathrm{i}}$, due to the overexpression of HCN2, may stimulate ACs and elevate cAMP. Then elevated cAMP may activate SERCA and potentially reduce $\left[\mathrm{Ca}^{2+}\right]_{\mathrm{i}}$ below control levels (Mons et al., 1998; Fig. 6), thereby inhibiting exocytic activity (Fig. 5). An increase in cAMP via the alternate route (dbcAMP) should then rescue exocytic activity, either by increasing local $\left[\mathrm{Ca}^{2+}\right]_{\mathrm{i}}$ (Yu et al., 2004; Zhong et al., 2004) or via activation of PKA-dependent mechanisms. While global $\left[\mathrm{Ca}^{2+}\right]_{\mathrm{i}}$ levels appeared unchanged (Fig. $6 c$ ), $\mathrm{Ca}^{2+}$ may still be increased locally, in exocytosis-relevant microdomains, resulting in the rescue of the rate of exocytic activity (Fig. $5 c, d$ ).

Kabaso et al. (2012) have proposed that rhythmic opening and closing of the fusion pore is related to the influx of cations into the vesicles. Cation influx takes place through HCN channels, which are near fusing vesicles (through the fusion pore and vesicular HCN channels and/or through the channels in the plasma membrane). Therefore, cation influx increases local cation concentration at the fusion pore. Inhibition of cation current with ZD7288 should then have the opposite effect. Indeed, ZD7288 significantly reduced the frequency of reversible exocytic events in our experiments (Fig. 5e,f). Basal $\left[\mathrm{Ca}^{2+}\right]_{\mathrm{i}}$ in HCN2-transfected cells and ZD7288-treated cells correlate well with the reduction in the rate of exocytic activity (Fig. 6e), which is an indication of a $\mathrm{Ca}^{2+}$ dependent mechanism. Nonetheless, impeded inflow of other cations and putative direct blocking effect by ZD7288, likely via interactions with the exocytic machinery (El-Kholy et al., 2007), may also play a role. Surprisingly, the addition of dbcAMP to ZD7288treated cells further inhibited the rate of exocytic activity, an effect presumably caused by the activation of SERCA pumps, which further reduced $\left[\mathrm{Ca}^{2+}\right]_{\mathrm{i}}$ in the absence of $I_{\mathrm{h}}$ (Fig. $6 c$ ).

In summary, our results demonstrate the role of $\mathrm{HCN}$ channels in regulated exocytosis in cultured rat lactotrophs. HCN channels modulate the rate of exocytic activity, likely via their role in the regulation of $\left[\mathrm{Ca}^{2+}\right]_{\mathrm{i}}$. Moreover, they appear to be involved in the regulation of fusion pore geometry, probably via electrostatic interactions due to changes in local cation concentration.

\section{References}

Angleson JK, Cochilla AJ, Kilic G, Nussinovitch I, Betz WJ (1999) Regulation of dense core release from neuroendocrine cells revealed by imaging single exocytic events. Nat Neurosci 2:440-446. CrossRef Medline

Ben-Tabou S, Keller E, Nussinovitch I (1994) Mechanosensitivity of voltage-gated calcium currents in rat anterior pituitary cells. J Physiol 476:29-39. Medline

Biel M, Schneider A, Wahl C (2002) Cardiac HCN channels: structure, function, and modulation. Trends Cardiovasc Med 12:206-212. CrossRef Medline

Calejo AI, Jorgačevski J, Silva VS, Stenovec M, Kreft M, Gonçalves PP, Zorec R (2012) Aluminium-induced changes of fusion pore properties attenuate prolactin secretion in rat pituitary lactotrophs. Neuroscience 201: 57-66. CrossRef Medline

Calejo AI, Jorgacevski J, Kucka M, Kreft M, Gonçalves PP, Stojilkovic SS, Zorec R (2013) cAMP-mediated stabilization of fusion pores in cultured rat pituitary lactotrophs. J Neurosci 33:8068-8078. CrossRef Medline 
Chernomordik LV, Kozlov MM (2008) Mechanics of membrane fusion. Nat Struct Mol Biol 15:675-683. CrossRef Medline

Cooper DM, Mons N, Karpen JW (1995) Adenylyl cyclases and the interaction between calcium and cAMP Signaling. Nature 374:421-424. CrossRef Medline

de Rooij J, Zwartkruis FJ, Verheijen MH, Cool RH, Nijman SM, Wittinghofer A, Bos JL (1998) Epac is a Rap1 guanine-nucleotide-exchange factor directly activated by cAMP. Nature 396:474-477. CrossRef Medline

El-Kholy W, MacDonald PE, Fox JM, Bhattacharjee A, Xue T, Gao X, Zhang Y, Stieber J, Li RA, Tsushima RG, Wheeler MB (2007) Hyperpolarizationactivated cyclic nucleotide-gated channels in pancreatic beta-cells. Mol Endocrinol 21:753-764. CrossRef Medline

Gauss R, Seifert R, Kaupp UB (1998) Molecular identification of a hyperpolarization-activated channel in sea urchin sperm. Nature 393: 583-587. CrossRef Medline

Gonzalez-Iglesias AE, Kretschmannova K, Tomic M, Stojilkovic SS (2006a) ZD7288 inhibits exocytosis in an HCN-independent manner and downstream of voltage-gated calcium influx in pituitary lactotrophs. Biochem Biophys Res Commun 346:845-850. CrossRef Medline

Gonzalez-Iglesias AE, Jiang Y, Tomić M, Kretschmannova K, Andric SA, Zemkova H, Stojilkovic SS (2006b) Dependence of electrical activity and calcium influx-controlled prolactin release on adenylyl cyclase signaling pathway in pituitary lactotrophs. Mol Endocrinol 20:2231-2246. CrossRef Medline

Hardel N, Harmel N, Zolles G, Fakler B, Klöcker N (2008) Recycling endosomes supply cardiac pacemaker channels for regulated surface expression. Cardiovasc Res 79:52-60. CrossRef Medline

Jorgacevski J, Stenovec M, Kreft M, Bajić A, Rituper B, Vardjan N, Stojilkovic S, Zorec R (2008) Hypotonicity and peptide discharge from a single vesicle. Am J Physiol Cell Physiol 295:C624-631. CrossRef Medline

Jorgacevski J, Fosnaric M, Vardjan N, Stenovec M, Potokar M, Kreft M, Kralj-Iglic V, Iglic A, Zorec R (2010) Fusion pore stability of peptidergic vesicles. Mol Membr Biol 27:65-80. CrossRef Medline

Jorgačevski J, Kreft M, Vardjan N, Zorec R (2012) Fusion pore regulation in peptidergic vesicles. Cell Calcium 52:270-276. CrossRef Medline

Kabaso D, Calejo AI, Jorgačevski J, Kreft M, Zorec R, Iglič A (2012) Fusion pore diameter regulation by cations modulating local membrane anisotropy. ScientificWorldJournal 2012:983138. Medline

Kasai H, Suzuki T, Liu TT, Kishimoto T, Takahashi N (2002) Fast and cAMP-sensitive mode of $\mathrm{Ca}^{2+}$-dependent exocytosis in pancreatic betacells. Diabetes 51:S19-S24. CrossRef Medline

Kaupp UB, Seifert R (2001) Molecular diversity of pacemaker ion channels. Annu Rev Physiol 63:235-257. CrossRef Medline

Kretschmannova K, Kucka M, Gonzalez-Iglesias AE, Stojilkovic SS (2012) The expression and role of hyperpolarization-activated and cyclic nucleotide-gated channels in endocrine anterior pituitary cells. Mol Endocrinol 26:153-164. CrossRef Medline

Lollike K, Lindau M (1999) Membrane capacitance techniques to monitor granule exocytosis in neutrophils. J Immunol Methods 232:111-120. CrossRef Medline

Michels G, Brandt MC, Zagidullin N, Khan IF, Larbig R, van Aaken S, Wippermann J, Hoppe UC (2008) Direct evidence for calcium conductance of hyperpolarization-activated cyclic nucleotide-gated channels and hu- man native If at physiological calcium concentrations. Cardiovasc Res 78:466-475. CrossRef Medline

Miklavc P, Mair N, Wittekindt OH, Haller T, Dietl P, Felder E, Timmler M, Frick M (2011) Fusion-activated Ca2 + entry via vesicular P2X4 receptors promotes fusion pore opening and exocytotic content release in pneumocytes. Proc Natl Acad Sci U S A 108:14503-14508. CrossRef Medline

Mons N, Decorte L, Jaffard R, Cooper DM (1998) Ca2+-sensitive adenylyl cyclases, key integrators of cellular signalling. Life Sciences 62:1647-1652. CrossRef Medline

Noam Y, Zha Q, Phan L, Wu RL, Chetkovich DM, Wadman WJ, Baram TZ (2010) Trafficking and surface expression of hyperpolarization-activated cyclic nucleotide-gated channels in hippocampal neurons. J Biol Chem 285:14724-14736. CrossRef Medline

Potokar M, Stenovec M, Kreft M, Gabrijel M, Zorec R (2011) Physiopathologic dynamics of vesicle traffic in astrocytes. Histol Histopathol 26:277284. Medline

Rituper B, Guček A, Jorgačevski J, Flašker A, Kreft M, Zorec R (2013) Highresolution membrane capacitance measurements for the study of exocytosis and endocytosis. Nat Protoc 8:1169-1183. CrossRef Medline

Schmidt U, Hajjar RJ, Kim CS, Lebeche D, Doye AA, Gwathmey JK (1999) Human heart failure: cAMP stimulation of SR Ca2+-ATPase activity and phosphorylation level of phospholamban. Am J Physiol 277:H474-H480. Medline

Seino S, Shibasaki T (2005) PKA-dependent and PKA-independent pathways for cAMP-regulated exocytosis. Physiol Rev 85:1303-1342. CrossRef Medline

Shi W, Wymore R, Yu H, Wu J, Wymore RT, Pan Z, Robinson RB, Dixon JE, McKinnon D, Cohen IS (1999) Distribution and prevalence of hyperpolarizationactivated cation channel $(\mathrm{HCN})$ mRNA expression in cardiac tissues. Circ Res 85:e1-e6. CrossRef Medline

Spruce AE, Breckenridge LJ, Lee AK, Almers W (1990) Properties of the fusion pore that forms during exocytosis of a mast cell secretory vesicle. Neuron 4:643-654. CrossRef Medline

Stojilkovic SS, Kretschmannova K, Tomić M, Stratakis CA (2012) Dependence of the excitability of pituitary cells on cyclic nucleotides. J Neuroendocrinol 24:1183-1200. CrossRef Medline

Vaccari T, Moroni A, Rocchi M, Gorza L, Bianchi ME, Beltrame M, DiFrancesco D (1999) The human gene coding for HCN2, a pacemaker channel of the heart. Biochim Biophys Acta 1446:419-425. CrossRef Medline

Vardjan N, Stenovec M, Jorgacevski J, Kreft M, Zorec R (2007) Subnanometer fusion pores in spontaneous exocytosis of peptidergic vesicles. J Neurosci 27:4737-4746. CrossRef Medline

Yu X, Duan KL, Shang CF, Yu HG, Zhou Z (2004) Calcium influx through hyperpolarization-activated cation channels (I(h) channels) contributes to activity-evoked neuronal secretion. Proc Natl Acad Sci U S A 101: 1051-1056. CrossRef Medline

Zhong N, Beaumont V, Zucker RS (2004) Calcium influx through HCN channels does not contribute to cAMP-enhanced transmission. J Neurophysiol 92:644-647. CrossRef Medline

Zorec R, Sikdar SK, Mason WT (1991) Increased cytosolic calcium stimulates exocytosis in bovine lactotrophs. Direct evidence from changes in membrane capacitance. J Gen Physiol 97:473-497. CrossRef Medline 